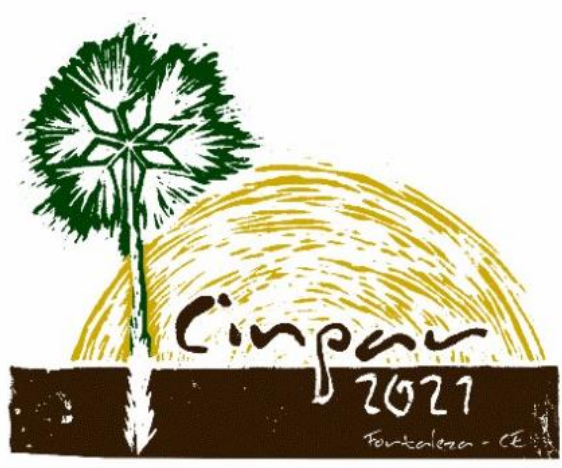

XVII Congresso Internacional sobre Patologia e

Reabilitação das Construções

XVII Congreso Internacional sobre Patología y Rehabilitación de las Construcciones

XVII International Conference on Pathology and Constructions Rehabilitation

FORTALEZA (Brasil), 3 a 5 de junho de 2021

https://doi.org/10.4322/CINPAR.2021.124

\title{
Reaproveitamento de fibra de coco como alternativa de adição ecológica para o melhoramento de propriedades mecânicas em argamassas
}

\section{Reuse of coconut fiber as an ecological addition alternative to improve the mechanical properties in mortars}

Júlio César Messias ARARUNA ${ }^{1}$, Mateus Rodrigues da COSTA², Monique Pereira BATISTA ${ }^{3}$, Gastão Coelho de AQUINO FILHO ${ }^{4}$, Francisco Lopes LAVOR NETO

\footnotetext{
${ }^{1}$ Instituto Federal da Paraíba, Cajazeiras-PB, Brasil, juliocesarmessias765@gmail.com

2 Universidade Federal da Paraíba, João Pessoa, Brasil, mateus.costa@academico.ufpb.br

${ }^{3}$ Instituto Federal da Paraíba, Cajazeiras-PB, Brasil, monique.pereira@academico.ifpb.edu.br

${ }^{4}$ Instituto Federal da Paraíba, Cajazeiras-PB, Brasil, gastao.aquino@ifpb.edu.br

${ }^{5}$ Instituto Federal da Paraíba, Cajazeiras-PB, Brasil, francisco.lavor@ifpb.edu.br
}

Resumo: A sustentabilidade atual se atrela com temas diversos, patologia das edificações é um destes uma vez que o melhoramento de propriedades dos materiais e otimização de sua utilização traz um decréscimo significativo no aparecimento destas. Assim, esse artigo tem como objetivo analisar a resistência à compressão axial, tração por compressão diametral e tração na flexão dos corpos de prova com diferentes teores de adição da fibra do coco, nas seguintes proporções: $0,0 \% ; 0,1 \% ; 0,2 \%$ e $0,3 \%$. Foram também realizados ensaios para a caracterização do agregado miúdo, do aglomerante e da fibra do coco.Verificou- se que o acréscimo da fibra na argamassa resultou em um melhor desempenho na resistência dos corpos de prova de $0,1 \%$ nos ensaios de tração por compressão diametral e compressão axial. No ensaio de tração na flexão, a resistência dos corpos de prova aumentou conforme aumentou a concentração de fibra, nos corpos com adição de fibra de coco. Pôde-se observar que não houve alteração significativa da consistência da argamassa, o que é bastante requerido nesse material. Sendo assim, a utilização de fibras de coco em argamassa implicou na melhora de propriedades mecânicas interessantes para diversas aplicações na construção.

Palavras-chave: Fibra de Coco, Argamassas, Ensaios Mecânicos, Resíduos Locais.

Abstract: Current sustainability is linked to different themes. The pathology of buildings is one of these since the improvement of material properties, and its use optimization brings a significant decrease in its appearance. Thus, this article aims to analyze the resistance to axial compression, Brazilian test, and flexural tests of samples with different levels of addition of coconut fiber. The addition teors was $0.0 \%, 0.1 \%, 0.2 \%$ and $0.3 \%$. Tests were also carried out to characterize fine aggregate, agglomerate, and coconut fiber. The fiber in the mortar resulted in a better performance in the resistance of the $0.1 \%$ specimens $0.1 \%$ in the brazilian tests and axial compression test. In the flexural tensile test, the strength of the models increased as the fiber concentration increased in the bodies with coconut fiber. It was observed that there was no significant change in the mortar's consistency, which is reasonably required in this material. Therefore, the use of coconut fibers in mortar has improved interesting mechanical properties for several construction applications.

Keywords: Coconut fiber, Mortars, Mechanical tests, Local waste. 


\section{Introdução}

Sustentabilidade é um dos temas mais discutidos no ramo da construção civil atualmente, visto que tal setor é uma das áreas que mais impactam no meio ambiente, desde o processo de extração e produção dos materiais, estendendo para seu transporte e processamento (CALDAS \& FILHO, 2019). Com isso, busca-se a implementação de novas técnicas e materiais que possam ser inseridos no meio produtivo de modo a atenuar seus efeitos negativos, uma vez que a construção civil é grande catalizador da economia do país, havendo a necessidade de sua conciliação com o desenvolvimento sustentável.

Junior \& Matsumoto explicam que um dos materiais mais utilizados na construção civil é a argamassa, sendo aplicada nos assentamentos de alvenarias, contrapiso, impermeabilização de superfície entre outras finalidades. Ainda segundo os autores, a utilização de argamassas como material de revestimento apresenta diversos aspectos positivos, tais como: facilidade do preparo e aplicação na obra, aderência, endurecimento e resistência.

Tendo em vista as aplicações para as quais a argamassa é destinada, e com isso as propriedades requeridas, Picanço (2005) afirma a importância de incorporar dosagens com materiais que auxiliem na obtenção de tais propriedades; sejam fibras naturais (fibras vegetais) ou mesmo sintéticas, a exemplo de polímeros industrializados.

Diante desse quadro, o estudo de materiais que atinjam o melhoramento de propriedades, e que estejam alinhados com o desenvolvimento sustentável, como o aproveitamento de resíduos locais tem ganhado espaço nos últimos anos, já que, segundo Conde, Stachiw e Ferreira (2014), a produção de resíduos é algo inevitável, restando ao homem minimizar os impactos causados pelos mesmos e dar uma destinação adequada a esses materiais.

Nesse contexto, o emprego de fibras naturais, a exemplo da fibra do coco, como reforço relaciona-se tanto a aspectos econômicos, como ambientais, por ser de baixo custo e ter grande disponibilidade (PICANÇO, 2005). Com isso, pretende-se analisar o desempenho mecânico das argamassas com e sem o emprego da fibra, utilizando-se de diferentes proporções, buscando, pois possível otimização de dosagem, e assim correlaciona-los com os seus usos na construção civil.

\section{Fundamentação Teórica}

\subsection{Argamassa:}

Segundo a NBR 13281:2005, argamassa é "uma mistura homogênea de agregado(s) miúdo(s), aglomerante(s) inorgânico(s) e água, contendo ou não aditivos ou adições, com propriedades de aderência e endurecimento".

Argamassa é um componente de destaque na construção civil, considerada como um componente de um conjunto e não separadamente como um material, sendo utilizado em funções fundamentais, tais como assentamento de alvenaria, contrapiso, garantindo também um bom acabamento onde é aplicada, impermeabilidade das alvenarias. Para tais são de grande importância algumas propriedades, como a trabalhabilidade de acordo com cada função, a capacidade de retenção de água, o equilíbrio químico e físico, a durabilidade, a capacidade de absorver deformação, resistência mecânica (RECENA, 2011).

De acordo com Recena (2011), a trabalhabilidade de uma argamassa vai depender de qual função irá realizar, logo não comprometendo o bom andamento da obra, e executando adequadamente o determinado objetivo. A quantidade de água na preparação da argamassa é o fator que mais influência na alteração da trabalhabilidade, ou seja, uma argamassa bastante fluida, sem coesão e com pouca consistência, não se torna trabalhável. Já uma argamassa com grande consistência e alta coesão comprometerá sua trabalhabilidade, uma vez que tornará dificultoso o trabalho.

\subsection{Fibra de coco:}

O coco (Cocus nucifera) é formado basicamente por quatro partes principais, sendo a fibra encontrada na região do mesocarpo, que é bastante espesso. As demais partes são: endosperma (ou polpa), endocarpo 
(parte rígida que protege a polpa) e epicarpo (casca externa), estando o mesocarpo entre o endocarpo e o epicarpo (BRAINER, 2018). Nesse sentido, a fibra de coco apresenta incontáveis vantagens que são desejáveis no meio da construção civil, principalmente no que diz respeito à durabilidade, como: inodora, resistente à umidade, não apodrece e não produz fungos (SENHORAS, 2003).

Com relação a composição das fibras, a celulose, que faz parte da estrutura básica de toda planta ou polímero, possui fortes ligações de hidrogênio, portanto considerada hidrofílica. Sendo assim, todas as fibras vegetais são hidrofílicas (AGRAWAL et al, 2000).

As propriedades da fibra do coco variam segundo vários fatores, "tais como o local de origem, composição química, maturação, espécie e método de extração" (TOMCZAK, 2010). Ainda assim, suas propriedades possuem alto grau de cristalinidade e polimerização, além de grandes moléculas, fazendo com que esse material tenha maior estabilidade aos efeitos de degradação, conferindo maior resistência mecânica, térmica, biológica e química do que os compostos formados por moléculas de pequeno porte (AGRAWAL et al, 2000).

Assim, por meio de resultados obtidos, Tomczac (2010) detectou que a tensão e a deformação na ruptura média tendem a diminuir conforme aumenta o comprimento da fibra; o efeito contrário ocorre com o módulo plástico, que aumenta à medida que o valor de seu comprimento cresce. Com relação à sua disponibilidade, Brainer (2018) afirma que a obtenção desse material é facilitada devido à sua disponibilidade, pois, para o coco, seja ele verde ou seco, não existe uma estação definitiva para o seu cultivo, que ocorre normalmente em dois períodos de maturação.

\section{Metodologia}

Essa pesquisa teve caráter experimental e teor descritivo, realizando uma abordagem quantitativa sobre as propriedades mecânicas da argamassa com e sem as fibras do coco. Foi realizada uma revisão bibliográfica sobre outros trabalhos que já trataram do tema e estudo das normas conforme foram sendo feitos os ensaios. Os testes foram realizados no Laboratório de Materiais de Construção Civil e no de Geotecnia do IFPB - Campus Cajazeiras.

No que diz respeito ao beneficiamento do material, foram extraídas as fibras do coco da região do mesocarpo. Logo após, as fibras passaram por um tratamento em meio ácido (Vinagre) por um período de 24 horas, objetivando remover a oleosidade do material, procedida de uma lavagem das fibras com água corrente, sendo posteriormente colocadas para a secagem na estufa a uma temperatura de $110{ }^{\circ} \mathrm{C}$ por um período de 4 horas. Procedimento semelhante é preconizado por Arsène (2013).

As fibras empregadas para a produção da argamassa tiveram um comprimento de $2 \mathrm{~cm}$ a $3 \mathrm{~cm}$, baseado em valores aproximados empregados por Soares et al (2012) e conforme valores ótimos encontrados por Silva et al (2014). Após isso, as mesmas passaram por ensaios de massa específica real e aparente, e teor de umidade inicial, seguindo os critérios utilizados por Izquierdo (2011).

O agregado miúdo a ser utilizado passou por um processo de caracterização por meio dos seguintes ensaios: Estudo granulométrico (NM 248 (ABNT, 2003)), Massa Unitária (NM 45 (ABNT, 2006)), Massa Específica Real e Aparente (NM 52 (ABNT, 2009)).

O aglomerante utilizado foi o cimento do tipo $\mathrm{CP}$ || Z - 32, cuja caracterização contemplou:

Quadro 1 - Caracterização do cimento (CP || Z - 32)

ENSAIO

MÓDULO DE FINURA

CONSISTÊNCIA

TEMPO DE PEGA

MASSA ESPECÍFICA

\section{NORMAS}

NBR $11579 / 2012$

NBR 16606/2018

NBR 16607/2018

NM 23/2000

Foram produzidos corpos de prova cilíndricos com $5 \mathrm{~cm}$ de diâmetro e $10 \mathrm{~cm}$ de altura para esse ensaio. Em sua pesquisa, Soares et al (2012) utilizou teores de fibra de $0,25 \%$ em adição à à massa total da argamassa. 
Sendo assim, visando obter teor otimizado de adição de fibra, confeccionou-se corpos de referência (aglomerante + agregado miúdo + água) e com concentrações de fibra (aglomerante + agregado miúdo + fibra de coco + água) em: $0,1 \%, 0,2 \%$ e $0,3 \%$. Para esse estudo, utilizou-se um traço convencional para contrapiso de 1:3 (cimento: areia). A quantidade de fibra foi calculada com base na massa do agregado e empregada em adição na mistura.

A confecção dos corpos de prova seguiu os requisitos indicados pela NBR 7215/2019, assim também como a preparação da argamassa e dos moldes. $O$ ensaio de consistência da argamassa foi realizado na flowtable, conforme a NBR 13276/2016.

Os testes de compressão axial, compressão diametral e tração na flexão foram realizados, respectivamente, segundo as normas NBR 12041/2013, NBR 7222/2011 e NBR 13279/2005, no período de 14 e 28 dias após sua produção os dois primeiros, e após os 28 dias para tração na flexão, não sendo realizado o ensaio com todos no mesmo tempo por falta de equipamento.

Conforme prevê a NBR $13279 / 2005$, as partes resultantes do ensaio de tração na flexão foram submetidas ao ensaio de compressão simples.

\section{Resultados}

\subsection{Agregado}

O estudo granulométrico do agregado miúdo resultou em diâmetro máximo de 4,8 $\mathrm{mm}$, e um módulo de finura de 2,51, o que caracteriza a areia como sendo média. A massa unitária do agregado é de 1,623 g/ $\mathrm{cm}^{3}$; a massa específica aparente do agregado seco de $2,36 \mathrm{~g} / \mathrm{cm}^{3}$, massa específica do agregado saturado superfície seca de $2,41 \mathrm{~g} / \mathrm{cm}^{3}$ e massa específica do agregado de $2,49 \mathrm{~g} / \mathrm{cm}^{3}$.

\subsection{Cimento}

Na caracterização do aglomerante foi obtido um módulo de finura de 3,66 \% e uma massa específica de 3,05 $\mathrm{g} / \mathrm{cm}^{3}$, conforme esperado para o cimento CP II Z - 32. Para a medição do tempo de pega, foi necessário, inicialmente, realizar seu teste de consistência, que resultou numa relação água-cimento de 0,273 . Seu tempo de início de pega foi 1 hora e 48 minutos; para o fim de pega, 2 horas e 4 minutos.

\subsection{Fibra de coco}

Nos ensaios de caraterização da fibra do coco, obteve-se que a mesma apresenta uma massa específica de $0,3165 \mathrm{~g} / \mathrm{cm}^{3}$ e um teor de umidade de $3,61 \%$, denotando uma densidade baixa relacionada à da água, que é de, aproximadamente, $1 \mathrm{~g} / \mathrm{cm}^{3}$. Ao realizar a comparação entre propriedades físicas e mecânicas das fibras mais utilizadas em materiais compósitos de matriz polimérica, Leão (2012) destaca que as fibras de coco possuem a menor massa específica comparada às fibras de vidro e demais fibras analisadas.

\subsection{Consistência de Argamassa}

No processo de produção da argamassa para a confecção dos corpos de prova, foi realizado, na mesa flowtable, o ensaio que mede a consistência de cada traço, que objetiva medir a trabalhabilidade da argamassa para os diferentes índices de fibra de coco usados, os quais tem relação direta com o seu uso.

Nesse sentido, segue o Figura 1 que apresenta esse comportamento: 


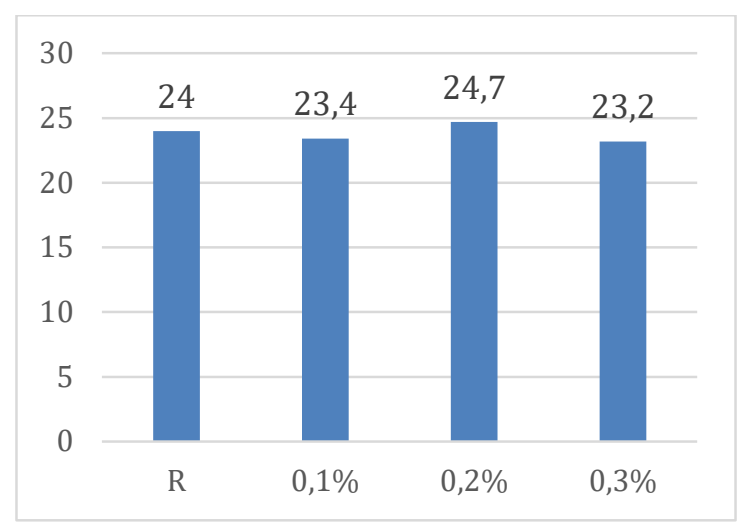

Figura 1 - Consistência média da argamassa

A partir da análise da Figura 1, nota-se que, para os teores de fibra analisados, não houve um padrão de decréscimo (ou acréscimo) da consistência conforme o aumento do teor de fibra, como fora esperado, entretanto nota-se que os valores são muito próximos, apresentando pequena variabilidade. Ainda assim, apesar do resultado presente para o teor de $0,2 \%$ de fibra, percebe-se uma diminuição pouco expressiva da consistência.

Com isso, para esses valores, o emprego da fibra pouco interfere na fluidez da argamassa, e, portanto, pouco influi na trabalhabilidade do material, o que é bastante requisitado, uma vez que a trabalhabilidade é uma característica requisitada na aplicação das argamassas.

Silva et al (2014), em sua pesquisa, concluiu que houve interferência da fibra nessa consistência, o que permite questionar a necessidade de investigar influência de fatores diversos, como tamanho das fibras, teor, traço, e outros, no que diz respeito à consistência.

\subsection{Compressão axial}

O ensaio de compressão axial diz respeito à aplicação de uma força centrada no eixo longitudinal dos corpos de prova cilíndricos, a qual é crescente e vai até a ruptura do material. Para a compressão axial, segue o Quadro 2 sobre seu comportamento:

Quadro 2 - Resistência à compressão axial - 14 e 28 dias

\begin{tabular}{r|rrrr} 
Teor de fibra & $\mathbf{F 1 4 ( N )}$ & $\mathbf{R 1 4}(\mathbf{M P a})$ & $\mathbf{F 2 8 ( N )}$ & $\mathbf{R 2 8 ( M P a )}$ \\
\hline $\mathrm{R}$ & 23978 & 12,22 & 25302 & 12,89 \\
$0,10 \%$ & 21804 & 11,11 & 27133 & 13,99 \\
$0,20 \%$ & 20595 & 10,49 & 20595 & 9,99 \\
$0,30 \%$ & 20987 & 10,26 & 21314 & 10,86
\end{tabular}

Assim, conforme mostra o Quadros 2, nota-se os corpos de prova com teores de 0,20 e 0,30\% apresentaram uma baixa na resistência com relação ao teor de $0,1 \%$ e de referência. Os corpos de prova com $0,10 \%$ de fibra apresentaram desempenho um pouco melhor que os corpos de referência a partir dos 28 dias, sendo para os 14 dias os valores de referência foram superiores. Tal resultado demonstra a melhora no comportamento da resistência à compressão, entretanto abre ressalvas para a relação que o teor de fibra apresenta, uma vez que maiores percentuais comprometeram sua resistência.

\subsection{Tração por compressão diametral}

A resistência à tração diz respeito de importante característica mecânica em argamassas com utilizações em assentamento de placas verticais, muitas vezes necessitando das elevadas espessuras que precisam de adição de malhas de aço galvanizado para garantir um melhor comportamento a tração.

No ensaio de tração por compressão diametral, a argamassa apresentou o comportamento descrito no Quadro 3 abaixo: 
Quadro 3 - Resistência à tração por compressão diametral - 14 dias e 28 dias

\begin{tabular}{c|cccc} 
Teor de fibra & $\mathbf{F}(\mathbf{N})$ & $\mathbf{R}(\mathbf{M P a})$ & $\mathbf{F}(\mathbf{N})$ & $\mathbf{R}(\mathbf{M P a})$ \\
\hline $\mathrm{R}$ & 10987 & 1,40 & 13996 & 1,78 \\
$0,10 \%$ & 14911 & 1,90 & 14911 & 1,90 \\
$0,20 \%$ & 8240 & 1,05 & 12164 & 1,55 \\
$0,30 \%$ & 10987 & 1,40 & 11314 & 1,44
\end{tabular}

O Primeiro ponto de destaque no Quadro 3 diz respeito à melhoria significativa dos resultados aos 28 dias, quando comparados aos 14 dias, o que é um resultado esperado. Tal ponto indica que a adição de fibras possui maior efetividade quando a matriz cimentícia apresenta maiores resistências uma vez que são maiores as tensões de confinamento sobre as fibras.

Observa-se que o teor de fibra de coco de $0,10 \%$ alcançou melhores resultados que os demais teores, tendo 0,20 e 0,30\% uma baixa na sua resistência, tal como para os ensaios de compressão axial. Tal resultado mais uma vez mostra uma melhora nas propriedades ocasionadas por uma adição pequena de fibra de coco na matriz cimentícia de argamassas, entretanto outros fatores encontram-se presentes nessa dinâmica, e são determinantes para que a adição de maiores teores implique na perda de propriedades.

Um desses fatores pode ser relacionado ao nível de empacotamento da mistura, uma vez que maiores concentrações de fibra tornam-se mais difíceis de homogeneizar, gerando assim zonas com fibras muito próximas não envolvidas pela matriz cimentícia, e portanto que não irão absorver os esforços. Outro ponto de destaque é que o tamanho das fibras utilizadas pode ter tido relação, dado que a efetividade da adição de fibras diz respeito à "ancoragem" que estas sofrem por entre os grãos de agregados, que no caso de argamassas possuem baixas granulometrias.

A adição de fibras confere certo nível de ductilidade à argamassa, diminuindo o efeito de ruptura busca, mas não o exaurindo, o que torna-se especialmente importante para aplicações em assentamentos verticais e para maiores níveis de solicitação das argamassas, uma vez que diminui o nível de fissuração.

\subsection{Tração na flexão}

O ensaio de tração na flexão corresponde a um ensaio normatizado, em que os corpos de prova, não mais cilíndricos, são prismáticos e retangulares, e simulam o comportamento de uma viga, cujo carregamento é aplicado transversalmente a seção da peça, sendo possível de observar na Figura 2 abaixo. Foi realizado o ensaio de tração flexão por três pontos, em que a carga é aplicada no meio do vão, e confere a viga um estado de flexão simples, porém com a definição do plano de ruptura no meio do vão.

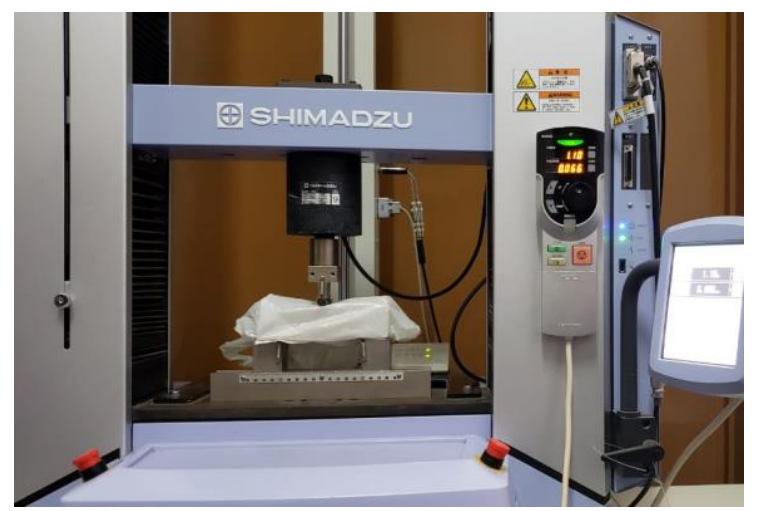

Figura 2 - Ensaio de Tração na Flexão - 3 Pontos

A realização desse ensaio baseia-se no fato que os esforços de flexão vão gerar uma esforços de tração (zona inferior) e compressão (zona superior) em cada seção do corpo de prova, e, com isso, ao aplicarmos pequenos carregamentos já é possível realizar o rompimento dos corpos de prova, uma vez que surge tração que pouco é resistida pelos materiais compostos por matriz cimentícia, como argamassa e concretos. 
Os resultados para a resistência a tração na flexão, encontram-se dispostos padronizados para a data de 28 dias, conforme a curva de crescimento destacada na NBR6118 (2014).

\begin{tabular}{c|c}
$\begin{array}{c}\text { Quadro 4 - Ensaio de tração na flexão } \\
\text { Teor de fibra }\end{array}$ & R(Mpa) \\
\hline $0,10 \%$ & 4,569 \\
$0,20 \%$ & 4,904 \\
$0,30 \%$ & 4,946
\end{tabular}

Conforme é destacado no Quadro 6, dentre as concentrações de fibras estudadas, a resistência da argamassa melhorou conforme foi aumentando o teor de fibra, tendo um melhor resultado os corpos de prova com 0,3 \%, padrão esse que não foi observado no ensaio de tração por compressão diametral.

Outro ponto que merece destaque diz respeito à ordem de grandeza dos resultados, já que os resultados de tração na flexão são maiores do que os de tração por compressão diametral. Tal fato é esperado pois a forma como é gerado o esforço de tração é diferente para tais casos, e com isso a maneira como a fibra é solicitada pode ser mais ou menos evidente.

Dessa forma, os resultados indicam que para solicitações de tração o aproveitamento da fibra é mais efetivo do que as trações obtidas por compressão diametral.

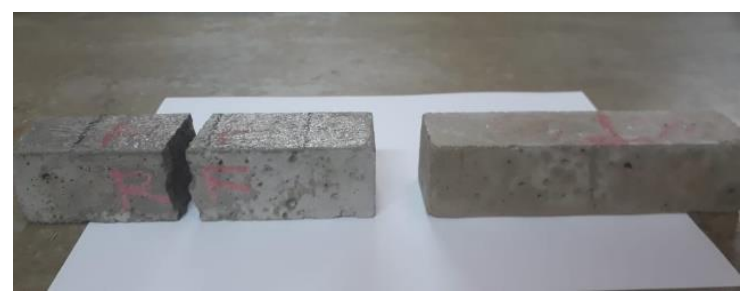

Figura 3 - Corpos de prova de referência e com fibra de coco após o ensaio de tração na flexão

Ao analisar a Figura 3, nota-se que tal como no ensaio de tração por compressão diametral a adição de fibras confere certa ductilidade a argamassa, de forma que esse passa a deformar um pouco mais antes que atinja a ruptura. A relação Força x Deformação do ensaio de tração na flexão deu-se conforme o gráfico a Figura 4.

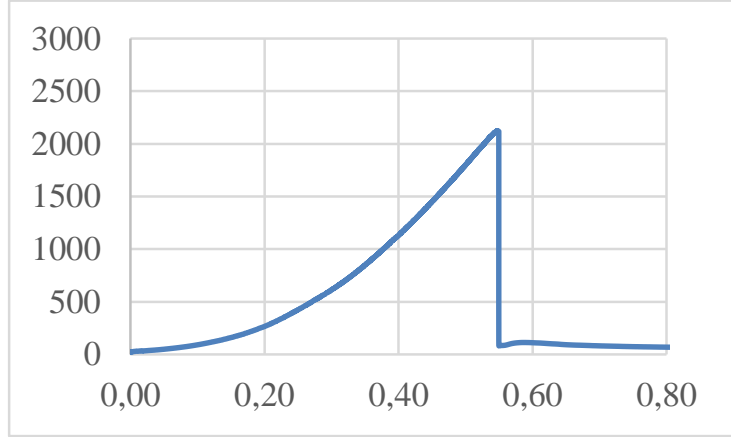

Figura 4 - Relação Força x Deslocamento CP com $0.3 \%$ fibra

\subsection{Compressão simples}

Tal ensaio é realizado com os corpos de prova rompidos durante o ensaio de tração na flexão, e também fornecem a ideia do comportamento a compressão do material.

O ensaio de compressão a partir das partes restantes do ensaio de tração na flexão em que os corpos de prova de $0,1 \%, 0,2 \%$ e $0,3 \%$ ensaiados são padronizados com relação à idade de 28 dias, por meio da curva de crescimento de resistência disposto na NBR 6118 (2014).

Os valores encontrados nesse ensaio constam no Quadro 5 a seguir: 


\begin{tabular}{|c|c|c|}
\hline \multicolumn{3}{|c|}{ Quadro 5-Ensaio de compressão simples } \\
\hline Teor de fibra & Fméd ( $N)$ : & fct,sc (Mpa) \\
\hline $0,10 \%$ & 21183 & 12,106 \\
\hline $0,20 \%$ & 21641 & 12,668 \\
\hline $0,30 \%$ & 26087 & 15,149 \\
\hline
\end{tabular}

Conforme mostra no Quadro 5, vê-se que o melhor desempenho foi para os corpos com teor de 0,3\% de fibra, e nota-se um padrão de elevação da resistência conforme o aumento da porcentagem de fibra. Notase que este padrão não segue o comportamento descrito durante os ensaios de compressão axial, entretanto ressalva-se que nesse ensaio a relação entre altura e comprimento é diferente do presente nos corpos de prova cilíndricos.

\section{Conclusão}

Ao final, tem-se que foram atingidos o objetivo deste trabalho, em que pontualmente destacam-se as seguintes contribuições:

a) A partir dos ensaios realizados, obteve-se a caracterização do material, com destaque a caracterização da fibra de coco local, que pode indicar um panorama inicial para caracterizações mais abrangentes em trabalhos futuros. Os ensaios de consistência indicaram que a argamassa com adição de fibra não teve sua trabalhabilidade afetada de forma significativa, visto que a variação estatística não foi significativa para os teores estudados;

b) Nos ensaios de tração por compressão diametral e compressão axial, constatou-se que, no geral, o melhor desempenho foi para os corpos de prova com $0,1 \%$ de fibra, sendo esse fato mais evidente na tração por compressão diametral. Os demais teores utilizados ficaram abaixo da resistência alcançada pelos corpos de referência;

c) No ensaio de tração na flexão e compressão simples, para os corpos com presença de fibra, notouse que quanto maior foi o teor de fibra, melhor os seus resultados, tendo o melhor desempenho, assim, os corpos de $0,3 \%$;

d) Contenção de fissuras e a conferência de certa ductilidade podem ser observados pela adição da fibra, o que é importante para argamassas utilizadas em assentamentos verticais e com maiores níveis de solicitação;

e) A utilização de fibras de coco em argamassa implicou na melhora de propriedades mecânicas relevantes para algumas aplicações, o que aliado com o apelo ambiental diz respeito a um importante destino para resíduos locais. 


\section{Referências Bibliográficas}

Agrawal, R.; Saxena, N. S.; Sharma, K. B.; Thomas, S.; Sreekala, M. S (2000). Activation energy and crystallization kinetics of untreated and treat oil palm fibre reinforced phenol formaldehyde composites. Materials Science \& Engineering, v. 277, p. 78-82.

Arsène, M. A., Bilba, K., Savastano Junior, H (2013). Treatments of Non-wood Plant Fibres Used as Reinforcement in Composite Materials, Materials Research, v.16, n.4, pp. 903-923.

ASSOCIAÇÃO BRASILEIRA DE NORMAS TÉCNICAS (2000). NM 23 - Cimento Portland e outros materiais em pó - Determinação da massa específica. Rio de Janeiro.

ASSOCIAÇÃO BRASILEIRA DE NORMAS TÉCNICAS (2003). NM 248 - Agregados - Determinação da composição granulométrica. Rio de Janeiro.

ASSOCIAÇÃO BRASILEIRA DE NORMAS TÉCNICAS (2005). NBR 13279 - Argamassa para assentamento e revestimento de paredes e tetos - Determinação da resistência à tração na flexão e à compressão.

ASSOCIAÇÃO BRASILEIRA DE NORMAS TÉCNICAS (2005). NBR 13281 - Argamassa para assentamento e revestimento de paredes e tetos. Rio de Janeiro.

ASSOCIAÇÃO BRASILEIRA DE NORMAS TÉCNICAS (2006). NM 45 - Agregados - Determinação da massa unitária e volumes vazios. Rio de Janeiro.

ASSOCIAÇÃO BRASILEIRA DE NORMAS TÉCNICAS (2009). NM 52 - Agregado miúdo - Determinação da massa específica e massa específica aparente. Rio de Janeiro.

ASSOCIAÇÃO BRASILEIRA DE NORMAS TÉCNICAS (2012). NBR 11579 - Cimento Portland - Determinação do índice de finura por meio da peneira $75 \mu \mathrm{m}$ ( $\mathrm{n}-200)$. Rio de Janeiro.

ASSOCIAÇÃO BRASILEIRA DE NORMAS TÉCNICAS (2013). NBR 12041 - Argamassa de alta resistência mecânica para pisos - Determinação da resistência à compressão simples e tração por compressão diametral. Rio de Janeiro.

ASSOCIAÇÃO BRASILEIRA DE NORMAS TÉCNICAS (2011). NBR 7222 - Concreto e armagassa - Determinação da resistência à tração por compressão diametral de corpos de prova cilíndricos. Rio de Janeiro.

ASSOCIAÇÃO BRASILEIRA DE NORMAS TÉCNICAS (2014). NBR 6118 - Projeto de estruturas de concreto Procedimento. Rio de Janeiro.

ASSOCIAÇÃO BRASILEIRA DE NORMAS TÉCNICAS (2016). NBR 13276 - Argamassa para assentamento e revestimento de paredes e teto - Determinação do índice de consistência. Rio de Janeiro.

ASSOCIAÇÃO BRASILEIRA DE NORMAS TÉCNICAS (2018). NBR 16606 - Cimento Portland - Determinação da pasta da consistência normal. Rio de Janeiro.

ASSOCIAÇÃO BRASILEIRA DE NORMAS TÉCNICAS (2018). NBR 16607 - Cimento Portland - Determinação dos tempos de pega. Rio de Janeiro.

ASSOCIAÇÃO BRASILEIRA DE NORMAS TÉCNICAS (2019). NBR 7215 - Cimento Portland - Determinação da resistência à compressão de corpos de prova cilíndricos. Rio de Janeiro.

Brainer, M. S. C. P (2018). Produção de coco: o Nordeste é destaque nacional. Caderno Setorial ETENE (Banco do Nordeste), Ano 3, № 61. Disponível em:

$<$ https://www.bnb.gov.br/documents/80223/4296541/61_coco.pdf/c172dd8f-3044-f1db-5d0ca94c5eb735e0>. Acesso em: 26 novembro 2019. 
Caldas, L. R.; Filho, R. D. T (2019). Avaliação ambiental de diferentes tipos e combinações de argamassas de revestimento utilizadas no Brasil. XII SBTA (Simpósio Brasileiro de Tecnologia das Argamassas), GoiâniaGO, p. 15-24. Disponível em:

<https://drive.google.com/file/d/1Sc0DhDKIdxMRuf6YWE7s2bOaVkdtEgnK/view>. Acesso em: 26 novembro 2019.

Conde, T. T; Stachiw, R.; Ferreia, E (2014). Aterro sanitário como alternativa para a preservação ambiental. Revista Brasileira de Ciências da Amazônia, Rondônia, v.3, n.1, p. 69-80. Disponível em:

<http://www.periodicos.unir.br/index.php/rolimdemoura/article/view/1183>. Acesso em: 26 novembro 2019.

Izquierdo, I. S. (2011). Uso de fibra natural de sisal em blocos de concreto para alvenaria estrutural. Dissertação de Mestrado. Escola de Engenharia de São Carlos, Universidade de São Paulo, São Carlos.

Junior, Luiz Carlos Gonçalves; Matsumoto, Marcio. Argamassa - como e onde devo usar ?. Disponível em : <https://www.aecweb.com.br/cont/m/rev/argamassas--como-e-onde-usar_11323_10_0>. Acessado em: 19 de novembro de 2018.

Leão, R. M (2012). Tratamento superficial de fibra de coco e aplicação em materiais compósitos como reforço do polipropileno. Tese (Doutorado) - Universidade de Brasília, Brasília.

Picanço, M. D. S (2005). Compósitos cimentícios reforçados com fibras de carauá. 2005. Dissertação (Mestrado em Engenharia Civil). Pontifícia Universidade Católica do Rio de Janeiro, Rio de Janeiro.

Recena, F. (2011). Conhecendo argamassa: 1 ed. Porto Alegre: EDIPUCRS.

Senhoras, E. M. (2003). Estratégias de uma agenda para a cadeia agroindustrial do coco: transformando a ameaça dos resíduos em oportunidades eco-eficientes; Monografia, Universidade Estadual de Campinas, Instituto de Economia, Campinas.

Silva, E. J. et al. (2014). Resistência à compressão de argamassas em função da adição de fibra de coco. Revista Brasileira de Engenharia Agrícola e Ambiental, Campina Grande, v. 18, n. 12. Disponível em: http://www.scielo.br/scielo.php?script=sci_arttext\&pid=S1415-43662014001200010\&lang=pt. Acesso em: 02 de dezembro 2019.

Soares, Elvis Andrade; et al. Determinação de propriedades mecânicas e físicas de argamassa reforçada com fibras de coco e sisal. 2012. Disponível em: <http://www.infohab.org.br/entac2014/2012/docs/1554.pdf>. Acessado em: 18 de novembro de 2018.

Tomczac, F. Estudos sobre a estrutura e propriedades de fibras de coco e curauá do Brasil. (2010). Tese (doutorado em Engenharia e Ciência dos Materiais) - Universidade Federal do Paraná (UFPA), Curitiba. 